\title{
Dual effects of melatonin on uterine myoelectrical activity of non-pregnant rats
}

\author{
Yavuz Simşek ${ }^{1}$, Hakan Parlakpınar ${ }^{2}$, Uğur Turhan³ ${ }^{3}$ Mehmet Emin Tağluk ${ }^{4}$, Burhan Ateş ${ }^{5}$ \\ 'Department of Obstetrics and Gynecology, Kirtkkale University Faculty of Medicine, Kirtkkale, Turkey \\ ${ }^{2}$ Department of Medical Pharmacology, Inönü University Faculty of Medicine, Malatya, Turkey \\ ${ }^{3}$ Department of Obstetrics and Gynecology, Inönü University Faculty of Medicine, Malatya, Turkey \\ ${ }^{4}$ Department of Electrical and Electronics, Inönü University Faculty of Engineering, Malatya, Turkey \\ ${ }^{5}$ Department of Chemistry, İnönü University Faculty of Science, Malatya, Turkey
}

\section{Abstract}

Objective: In this experimental study, we aimed to investigate the role of melatonin on uterine myoelectrical activity of non-pregnant rats.

Material and Methods: Forty-six female rats were assigned to six groups: (1) control; ( $0.2 \mathrm{~mL} 0.9 \% \mathrm{NaCl}$ was injected intravenously (IV), $\mathrm{n}=6$ ); (2) melatonin applied as $0.4 \mathrm{mg} / \mathrm{kg} / \mathrm{IV}(\mathrm{n}=8)$; (3) melatonin applied as $4 \mathrm{mg} / \mathrm{kg} / \mathrm{IV}(\mathrm{n}=8)$; (4) single dose of oxytocin (100 mU/kg) injected IV $(\mathrm{n}=8)$; (5) melatonin $(0.4 \mathrm{mg} / \mathrm{kg})$ plus oxytocin $(100 \mathrm{mU} / \mathrm{kg})(\mathrm{n}=8)$; and (6) melatonin $(4 \mathrm{mg} / \mathrm{kg}) \mathrm{plus}$ oxytocin $(100 \mathrm{mU} / \mathrm{kg}) \mathrm{injected} \mathrm{IV} \mathrm{(n=8).}$ Each rat underwent a laparotomy, and uterine myoelectrical signals were recorded. The mean spectrum, averaged over the spectral content of signals in each group, was compared.

Results: Melatonin induced uterine myoelectrical activity in a dose-dependent manner. Treatment of melatonin after oxytocin suppressed the mean power of the signals. Serum melatonin concentrations were significantly higher in melatonin-treated rats.

Conclusion: Melatonin itself at two different dose levels was found to be equally effective in stimulating the uterine electrical signals, although oxytocin-induced uterine electrical activity was suppressed by melatonin. These findings merit further investigations on the possible beneficial role of melatonin in the treatment of conditions associated with abnormal uterine activity. (J Turk Ger Gynecol Assoc 2014; 15: 86-91)

Key words: Uterine contraction, melatonin, oxytocin, electrical stimulation

Received: 15 December, $2013 \quad$ Accepted: 29 December, 2013

\section{Introduction}

Plasma oxytocin throughout pregnancy is very low in the daytime and changes to the highest level at nighttime $(1,2)$. This change has been reported to parallel diurnal changes in uterine contractions (2). This is why the onset of labor, particularly in human primates, generally transpires during nighttime (3). It has been reported that uterine contraction frequency increases between 20:30 and 02:00 in humans, which interestingly coincides with maximal pineal melatonin secretion (4).

Melatonin is a peptide hormone secreted by the pineal gland in a circadian manner and is released into the vascular system. Its higher levels occur during midnight in all species (5). Several physiological processes, such as the sleep-wake cycle and endocrine function of various glands, have been regulated by melatonin secretion (6). It was suggested that serum melatonin levels differ throughout gestation. The first half of pregnancy is characterized by elevated levels of melatonin; however, between 20-36 weeks, melatonin levels decrease, and from that time to the end of pregnancy, the levels rise again (7).

In a few previous investigations, it has been shown that uterine myocytes express both melatonin-1 and melatonin-2 receptors (8). In recent years, several studies have been conducted for investigating a significant correlation between uterine contraction dynamics and melatonin level; nonetheless, inconsistent results have been reported (9-11). Despite these results being contradictory, in addition to melatonin's prime effects on reproductive mechanisms, all of these studies indicate the existence of an uncharacterized relation between melatonin level and uterine contractility.

While the beneficial effects of melatonin in different tissues have been studied by researchers, to our best knowledge, there is no any information regarding the effects of melatonin in different concentrations on contraction patterns of the nonpregnant rat uterus (12-15). On the basis of this background, using an in vivo experimental model, we aimed to explore the physiological and pharmacological concentrations of melatonin on spontaneous and oxytocin-induced contraction patterns of a non-pregnant rat uterus. 


\section{Material and Methods}

\section{Animal Care}

Forty-six adult female Wistar albino rats, aged 11-13 weeks and weighing 200-350 g, were purchased from the Inonu University Laboratory Animals Research Center and placed in a temperature $\left(21 \pm 2^{\circ} \mathrm{C}\right)$ - and humidity-controlled $(60 \pm 5 \%)$ room, in which a 12:12 h light: dark cycle was maintained. The rats had free access to standard dry pellets ad libitum and tap water to the end of the investigation. Each step of the study protocol was done in accordance with the animal research guidelines of the National Institutes of Health, and ethical approval was obtained from the local ethic committee of Inonu University Faculty of Medicine.

Before uterine exposition, all animals were synchronized hormonally in their 4-day estrus stages in order to eliminate the differences in steroid synthesis, and thus, uterine myoelectrical activity was recorded between the individual animals, and then the obtained signals were analyzed. Hormonal synchronization was done by subcutaneous injections of $55 \mathrm{mg} / \mathrm{kg}$ body weight estradiol with two doses $24 \mathrm{~h}$ apart, followed by one injection of $7.5 \mathrm{mg} / \mathrm{kg}$ body weight of progesterone $20 \mathrm{~h}$ after the last estradiol dose (16).

In order to determine the estrous cycle of each rat, vaginal smears of the rats were taken by a cotton swab daily; the swab was inserted into the vagina of rats and rotated $360^{\circ}$ clockwise; then, the swab was smeared onto a glass slide. Smears were stained by Papanicolaou method and then evaluated through a Leica DFC280 light microscope by a pathologist who was blind to the groups. The estrous cycle was diagnosed as follows: proestrus period (epithelial cells with centrally nucleolated), estrus period (unnucleated and cornified epithelial cells), metestrus period (a few cornified cells with leukocytes and mucus), and diestrus period (a number of epithelial cells, mucus, and leukocytes).

\section{Drug Preparation and Treatment}

All rats were first weighed and then anesthetized with xylazine $(8 \mathrm{mg} / \mathrm{kg})$ and ketamine hydrochloride $(75 \mathrm{mg} / \mathrm{kg})$, which were intraperitoneally (i.p.) administered. The rats were randomly assigned (using random number tables) to six groups as follows: (1) control; ( $0.2 \mathrm{~mL} 0.9 \% \mathrm{NaCl}$ was injected intravenously (IV) via the jugular vein, $n=6$ ); (2) melatonin applied as $0.4 \mathrm{mg}$ / $\mathrm{kg} / \mathrm{IV}$ (physiological dose, $\mathrm{n}=8$ ); (3) melatonin applied as $4 \mathrm{mg} /$ $\mathrm{kg} / \mathrm{IV}$ (pharmacological dose, $\mathrm{n}=8$ ); (4) single dose of oxytocin $(100 \mathrm{mU} / \mathrm{kg})$ injected IV $(\mathrm{n}=8) ;(5)$ melatonin $(0.4 \mathrm{mg} / \mathrm{kg})$ plus oxytocin (100 mU/kg) $(\mathrm{n}=8)$; and (6) melatonin (4 mg/kg) plus oxytocin $(100 \mathrm{mU} / \mathrm{kg})$ injected IV $(n=8)$. The drug treatments were administered as a bolus injection via a right jugular venous catheter, which was performed under general anesthesia. Melatonin (Sigma Chemical Co., St Louis, MO, USA), used in this experiment, was dissolved in ethanol and diluted in saline to achieve a final concentration of $1 \%$ in ethanol.

\section{Myoelectrical Activity Measurement}

The recording of the electrical activity of uterine myofibrils was performed with a BIOPAC MP100 A-CE data acquisition system (model MP100; version 3.7.2; Goleta, CA, USA) with a 1000 preamplifier gain (this preamplifier gain was compensated later through signal processing) and a sampling frequency of $500 \mathrm{~Hz}$. Each rat underwent a laparotomy, and bipolar electrodes were subserously inserted into the uterine horn $1 \mathrm{~cm}$ apart from each other. The reference electrode was inserted on the left leg of animals, and the uterine myoelectrical activity was recorded for at least 5 min under general anesthesia. The signal recording was started 60 seconds after the injection of medication in each group for the stabilization period. The signals were examined by a specific program that was developed by the same research group using the Matlab (R6; The MathWorks, Natick, MA, USA) environment.

\section{The Signal Analysis Method}

The signals recorded from the uterine horns of each rat were analyzed for assessment of the effect of the given remedy. Since the strategy in this study was not based on exciting and recording the response, it was not thought that the time domain signals would provide a good marker for the given treatment common to all subjects within one group. The temporal average of signals over the subjects in each group may cancel the characteristic representations that can be linked to the medication. This cancellation could be due to unpredictable phase shifts between individual signal components. However, it was considered that a sort of correlation that goes between all the signals in each group should exist and that this correlation signal should give information regarding the format of the uterine contractions common to the individual group under consideration. Obviously, a permutative correlation process intervening between each pair of uterine signals would take too much time. So, instead of the correlation process in the time domain, the mean spectrum averaged over the spectral content of the signals of subjects in each group was simply taken into account for the assessment. Although these signals are, in fact, time-varying signals that may not be really processed through Fourier transform, we only focused on the existence of a common spectral content rather than the temporal evolution of each component. Otherwise, the process would be meaningless. Basically, the mean spectrum averaged over the signals in each group was calculated as:

$$
S(f)=\frac{1}{N} \sum_{n=1}^{N} \int_{-\infty}^{+\infty} s_{n}(t) e^{-j 2 \pi f t} d t
$$

(1) where $s(t)$ stands for temporal uterine electrical activity and $\mathrm{N}$ is the number of subjects per group. The spectral signal, $\mathrm{S}(\mathrm{f})$, obtained from this process was considered as carrying characteristic features common to the group, which, therefore, should correlate to the medication given to the rats in the group. Note that the temporal signal is first converted into an analytical form through Hilbert transform, such that $s(t)=u(t)+j H(u(t))$. The Hilbert transform of a given uterine electrical signal $u(t)$ can be defined as: 


$$
\mathrm{H}(u(t))=\frac{1}{\pi} \mathrm{P} \cdot \mathrm{v} \sum_{n=1}^{N} \int_{-\infty}^{+\infty} \frac{u(\tau)}{t-\tau} d \tau
$$

(2) where P.v. is the Cauchy principal value and $\tau$ is the time delay (17). Then, the analytical signals were filtered with a secondorder Butterworth band-pass filter with cutoff frequencies of 0.3 $\mathrm{Hz}-45 \mathrm{~Hz}$. Finally, the power spectra of these complex analytical uterine signals were accomplished using equation (1).

\section{Extraction of Melatonin in Serum Samples}

To measure the melatonin concentration, $100 \mu \mathrm{L} 2 \mathrm{M}$ tricarboxylic acid (TCA) was added to $1.0 \mathrm{~mL}$ of serum samples. After $10 \mathrm{~min}$ in an ice bath, the mixture was centrifuged (5000 g, $10 \mathrm{~min}$ ), and the $\mathrm{pH}$ of the supernatant was adjusted to 7.0 by the addition of $10 \mu \mathrm{L} 2 \mathrm{M} \mathrm{NaOH}$. The aqueous sample was added to the top of disposable Waters Oasis HLB (1 cc, $30 \mathrm{mg}$ ), conditioned using methyl alcohol $(1 \mathrm{~mL})$ and water $(1 \mathrm{~mL})$. Organic extraction was performed with $2 \mathrm{ml}$ dicholoromethane. The extract was concentrated by evaporation in a nitrogen gas system. The residue was then reconstituted in $100 \mu \mathrm{L}$ of mobile phase, and $20 \mu \mathrm{L}$ of this solution was injected into the chromatograph.

\section{Chromatography}

Plasma melatonin concentration was determined by a sensitive high-performance liquid chromatographic (HPLC) method. The HPLC system was equipped with an LC-10 AD pump, fluorescence detector, and an SIL-AAAD Autosampler (Agilent, USA). Melatonin was separated using an ODS-2 (150x4.6 mm, $5 \mu \mathrm{m})$ column. The HPLC mobile phase consisted of $75 \mathrm{mM}$ sodium acetate-acetonitrile $(72: 28, \mathrm{v} / \mathrm{v})(\mathrm{pH} \mathrm{5.0})$. The flow rate was 1.0 $\mathrm{ml} / \mathrm{min}$. The fluorimetric detector was set at an excitation wavelength of $275 \mathrm{~nm}$ and an emission wave length of $345 \mathrm{~nm}$. The peak area was used as a measure of the detector response. The level of melatonin in serum samples was calculated by using an external melatonin standard.

\section{Statistical Analysis}

For detecting even minor effects, the required sample sizes used in this experiment were identified using statistical power analysis. The sample sizes necessary for a power of 0.80 were estimated using NCSS software. The normality of the distribution was controlled by Shapiro-Wilk test. According to the results obtained from the normality test, Kruskal-Wallis $\mathrm{H}$ test was used for the statistical analysis as appropriate. After a significant Kruskal-Wallis $\mathrm{H}$ test, Conover test was carried out. $\mathrm{p}<0.05$ was accepted as statistically significant. The values were given as medians (Min-Max). Data were analyzed using the SPSS software program, version 18.0, for Windows (SPSS Inc., Chicago, IL, USA).

\section{Results}

\section{Analysis of the Electrical Signal}

The recorded uterine electrical signals were vague; so, many statistical means were tried for classifying them, but the suc- cess rate was very low. So, these trials were not taken into account here. Figure 1 shows the typical uterine electrical activity of each group. These temporal signals show variations, even within groups, so that we could not succeed in classifying them. The group-based mean spectral signals obtained in this study are shown in Figure 2. These signals contain some information regarding the uterine contractions that may indirectly specify the format of the uterine contractions common to the group.

As the mean spectrum signals given in Figure 2 were analyzed, one can easily notice the fundamental narrow spectral bands that may be named spectral components (each band may be composed of two or more very closely time-limited oscillating harmonics). From this point of view, Group 1 comes up with two significant spectral components centered around $0.6 \mathrm{~Hz}$ and $1.1 \mathrm{~Hz}$. Group 2 also comes up with two components: one centered around $0.65 \mathrm{~Hz}$ and the other around $1.2 \mathrm{~Hz}$. The significant spectral components for Group 3 were somewhat different, as three narrow-band components centered at 0.55 $\mathrm{Hz}, 0.67 \mathrm{~Hz}$, and $0.75 \mathrm{~Hz}$, respectively. These components were apparently much more powerful than the components that appeared in other groups. In the case of Group 4, the components were centered at $0.48 \mathrm{~Hz}, 0.8 \mathrm{~Hz}$, and $1.21 \mathrm{~Hz}$, respectively, with a much narrower band (as seen from the figure, each band almost contained a single oscillating component). As these three components were artificially created, the signal showed the characteristics of the natural burst demonstrated by the oxytocin-induced rats (Figure 3 ). These results clearly show the precision of the experiment conducted here. Interestingly, Group 5 demonstrated only one component at $0.55 \mathrm{~Hz}$, while Group 6 also showed one component, located at $1 \mathrm{~Hz}$.

\section{Serum Melatonin Results}

The mean melatonin levels in each group are shown in Table 1. In brief, both the endogenous physiological dose of melatonin $(0.4 \mathrm{mg} / \mathrm{kg})$ and pharmacological dose of melatonin $(4 \mathrm{mg} /$ $\mathrm{kg}$ ) caused an elevation in serum melatonin concentrations when compared to the control group. There was no difference between the control and oxytocin groups. Supplementations of both melatonin doses to the oxytocin group showed significant elevation, according to the oxytocin-treated alone group.

\section{Discussion}

In this experimental study, it is clearly presented that melatonin treatment alone can induce uterine myoelectrical activity in a dose-dependent manner, similar to the oxytocin in nonpregnant rats. Another remarkable finding of the present study is that the treatment of melatonin after oxytocin caused the mean power of the signal to reduce, which thereby means that it inhibits the physiological contractile effect of oxytocin on the uterus. To the best of our knowledge, this is the first time that these observations have been presented in an in vivo experimental study.

Previously, Ayar et al. (18) reported that melatonin can prevent prostaglandin production and suppress native and oxytocinstimulated uterine contraction. On the contrary, however, Ma“rtensson et al. (19) reported that melatonin exposure after 
Table 1. The mean melatonin levels in each group

\begin{tabular}{|l|c|c|}
\hline Groups & $\begin{array}{c}\text { Melatonin level (pg/mL) } \\
\text { Median (min-max) }\end{array}$ & $\begin{array}{c}\text { Different from } \\
\mathbf{( p < 0 . 0 5 )}\end{array}$ \\
\hline Group 1 (Control) & $3.93(1.96-28.52)$ & $(2),(3),(5),(6)$ \\
\hline Group 2 (0.4 mg/kg melatonin) & $554.87(289.36-791.17)$ & $(1),(4)$ \\
\hline Group 3 (4 mg/kg melatonin) & $617.23(288.00-754.28)$ & $(1),(4)$ \\
\hline Group 4 (100 mU/kg oxytocin) & $42.90(3.73-693.50)$ & $(1),(4)$ \\
\hline $\begin{array}{l}\text { Group 5 (0.4 mg/kg melatonin }+ \\
100 \mathrm{mU} / \mathrm{kg} \text { oxytocin) }\end{array}$ & $513.21(267.54-615.04)$ & $(1),(4)$ \\
\hline $\begin{array}{l}\text { Group 6 (4 mg/kg melatonin }+ \\
100 \mathrm{mU} / \mathrm{kg} \text { oxytocin) }\end{array}$ & $658.44(458.05-1325.44)$ & \\
\hline
\end{tabular}

noradrenalin administration to human myometrial strips can induce the contraction of myofibrils. More recently, Sharkey et al. (20) reported that melatonin acts synergistically via the melatonin receptor 2/phospholipase C/protein kinase C (MT2R/PLC/ $\mathrm{PKC}$ ) signaling pathway to markedly increase the sensitivity of myofibrils to oxytocin and augment oxytocin-stimulated contractility. In this report, they suggested that treatment with physiological concentrations of melatonin stimulates both basal and oxytocin-triggered contractility of uterine myofibrils. Contrary to the results above, Taketani et al. (21) recently suggested that melatonin protects ovarian granulosa cells from reactive oxygen species-dependent damage and stimulates progesterone production, which suppresses uterine contractility in women undergoing in vitro fertilization and embryo transfer procedures. In the present study, after oxytocin induction, melatonin treatment caused suppression of the rat's uterine myoelectrical activity-that is, our finding is in concordance with those reporting the inhibitory role of melatonin on the uterine contractility induced by oxytocin.

The exact mechanisms for the contractile or relaxing actions of melatonin, however, remain to be elucidated. According to Schlabritz-Loutsevitch et al. (22), these differences are likely to relate to differences in the phase relation between nocturnal melatonin secretion and maximal myometrial contractile activity (high at night in primates; high during the day in rodents). Gimeno et al. (23), on the other hand, suggested that melatonin can have a suppressive effect on uterine contractility by inhibition of prostaglandin production in vitro. Furthermore, our data show for the first time that melatonin has a unique dual effect on the rat uterus in vivo, including the individual excitation of uterine myoelectrical activity and the suppression of oxytocininduced uterine contractile signals in a dose-dependent manner (Table 1) (Figure 1, 2).

Although the signal components for Groups 5 and 6 seem to be powerful enough from a signal point of view, since they are single oscillating components, they do not able to generate impulsive components to stimulate myometrial muscular cells. As also seen from Figure 1, treatment with higher-dose melatonin after oxytocin caused the mean power of signal to reduce, which means that it inhibits the physiological effect of oxytocin. From a power viewpoint in Group 3, the pharmacological dose of melatonin provokes powerful components, but this may not lead directly to powerful contractions, due to possessing lower

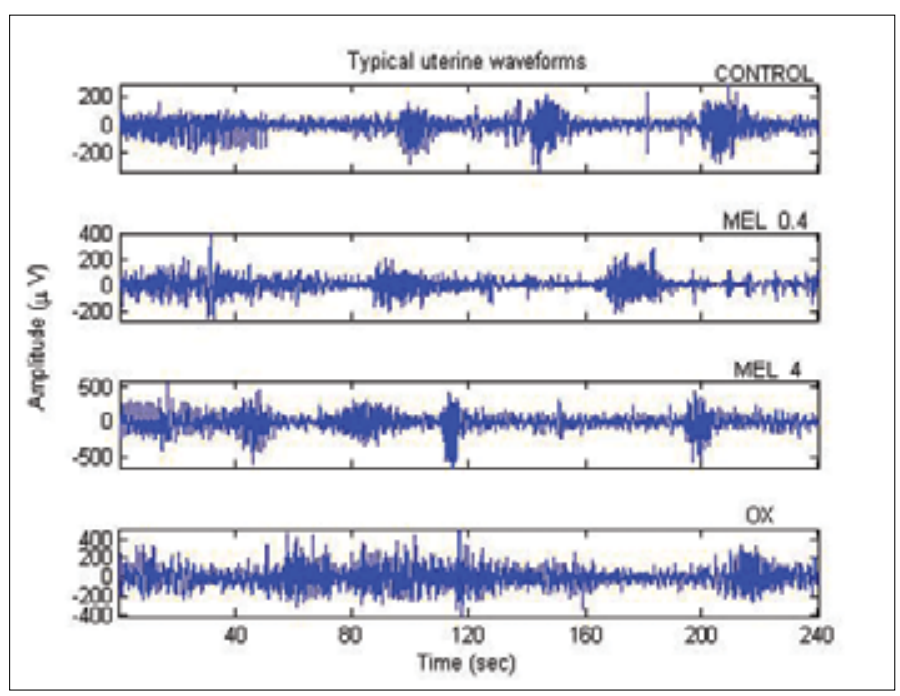

Figure 1. Typical uterine electrical signals recorded from nonpregnant rats

frequencies than those rats treated with oxytocin alone.

Similarly, Abd-Allah et al. (24) reported that melatonin pretreatment of rats for 15 consecutive days markedly reduced the number of uterine estrogen receptors by $59 \%$, with a concomitant increase in progesterone receptors by $34.7 \%$. Additionally, they showed prominent suppression in the uterine response to oxytocin in rats treated with melatonin. These observations may suggest that suppression of estrogenic activity on the myometrium is one of the possible mechanisms of a blocking effect of melatonin on oxytocin induced-uterine contractions.

In the current experiment, the effects of oxytocin and melatonin on the uterine myoelectrical activity of non-pregnant rats were investigated using signal processing techniques. Signal processing techniques provide useful information regarding uterine activity. The effectiveness of such methods has previously been discussed by our group (25). Therefore, the results obtained here have the potential to be translated into clinical therapy, as melatonin is a common product that is available as a dietary supplement that is suitable for use during pregnancy (26). In obstetrical practice, preterm delivery is one of the most common pregnancy complications and the leading factor of neonatal mortality and morbidity $(27,28)$. It has been concluded that the use of currently known tocolytic agents in cases of preterm 


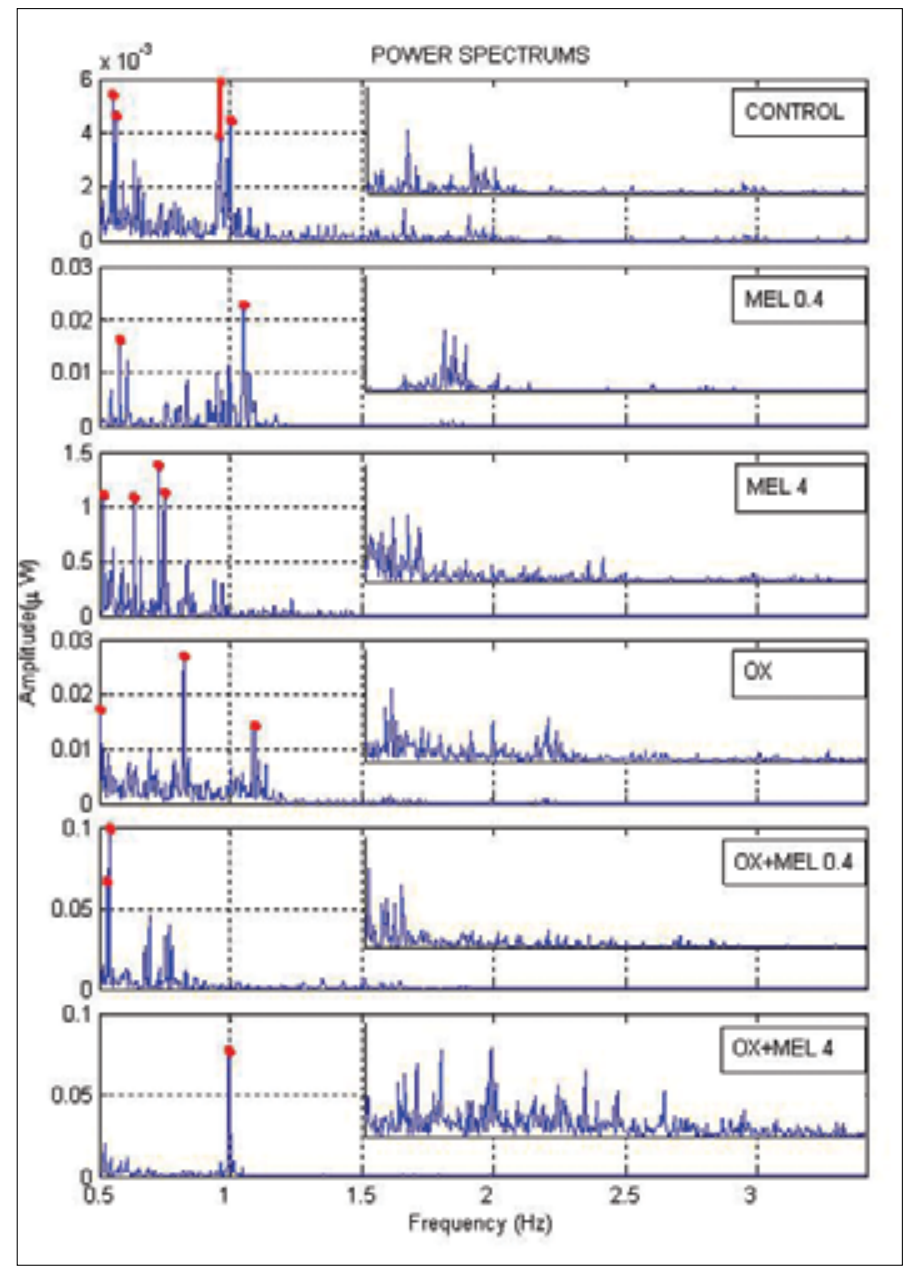

Figure 2. Group-based spectra of uterine electrical activity obtained from non-pregnant rats

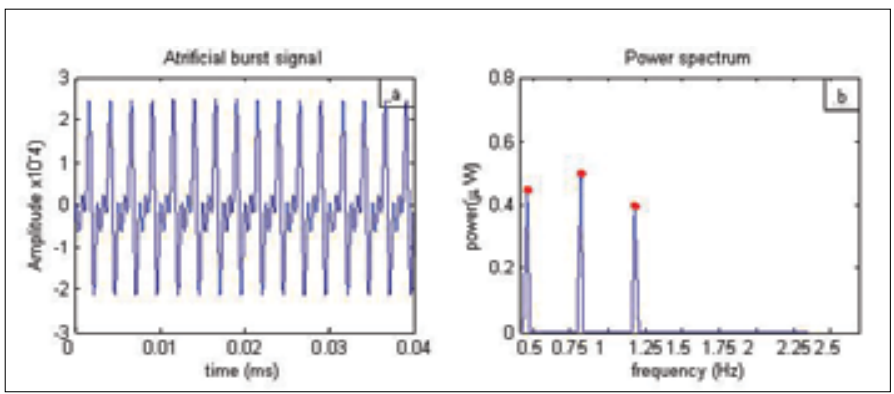

Figure 3. a, b. A synthetic signal simulating the uterine signal treated with oxytocin (a) and its spectrum (b)

labor does not reduce neonatal morbidity and mortality (29). Concerning both the results of previous studies and the results obtained in this study, as an alternative option, it might be valuable to suggest that melatonin itself or its agonists for treatment of pregnants with premature uterine contractions. Since Parlakpinar et al. (30) reported that the pineal gland atrophies and its melatonin secretion significantly decreases in geriatric cases, who are not capable of pregnancy, a new experimental study can be planned in pinealectomized rats for evaluating the effects of the lack of chronic physiological melatonin on uterine tissue.

In the current study, also, the mean melatonin levels among the groups were determined for reflecting the basal melatonin status (for Groups 1 and 4) and the response sensitivity of melatonin treatments in the melatonin alone and combined groups (for Groups 1, 2, 5, and 6) (Table 1). Therefore, the discussion section was designed and more detailed, according to the obtained serum melatonin results and uterine myoelectrical signals.

In fact, this experimental study has a number of limitations, such as the small size of groups and lack of intrauterine pressure measurement. The small size issue was due to our ethical concern; however, much larger numbers would be useful to make a brilliant conclusion on the topic. Evaluation of intrauterine pressure together with the results obtained through signal processing would certainly be more valuable to discuss directly the effects of melatonin on either spontaneous or oxytocininduced uterine contractions.

As a final conclusion, it is possible to report that melatonin alone stimulates, but melatonin after oxytocin treatment reduces the myoelectrical activity in non-pregnant rats, which demonstrates the dual effect of melatonin on the contractility of the uterus.

Ethics Committee Approval: Ethics committee approval was received for this study from the ethics committee of Inönü University Faculty of Medicine.

\section{Informed Consent: N/A.}

Peer-review: Externally peer-reviewed.

Author contributions: Concept - Y.S., H.P., M.E.T.; Design - H.P., Y.S. M.E.T, ; Supervision - Y.S.,; Resource - Y.SS., H.P.; Materials Y.S., H.P., U.T., M.E.T, B.A. ; Data Collection\&/or Processing - H.P., Y.S., U.T.; Analysis\&/or Interpretation - M.E.T, Y.S..; Literature Search - Y.S., H.P., M.E.T.; Writing - Y.S., M.E.T., H.P.; Critical Reviews - M.E.T.

Conflict of Interest: No conflict of interest was declared by the authors.

Financial Disclosure: The authors declared that this study has received no financial support.

\section{References}

1. Fuchs AR, Behrens O, Liu HC. Correlation of nocturnal increase in plasma oxytocin with a decrease in plasma estradiol/progesterone ratio in late pregnancy. Am J Obstet Gynecol 1992; 167: 1559-63. [CrossRef]

2. Wilson L Jr, Parsons MT, Flouret G. Forward shift in the initiation of the nocturnal estradiol surge in the pregnant baboon: is this the genesis of labor? Am J Obstet Gynecol 1991; 165: 1487-98. [CrossRef]

3. Anderka M, DeClercq ER, Smith W. A time to be born. Am J Public Health 2000; 90: 124-6. [CrossRef]

4. Zahn V, Hattensperger W. Circadian rhythm of pregnancy contractions. Z Geburtshilfe Perinatol 1993; 197: 1-10.

5. Hardeland R. Melatonin metabolism in the central nervous system. Curr Neuropharmacol 2010; 8: 168-81. [CrossRef]

6. Reiter RJ, Tan DX, Manchester LC, Paredes SD, Mayo JC, Sainz RM. Melatonin and reproduction revisited. Biol Reprod 2009; 81: 445-56. [CrossRef] 
7. Kilvela A. Serum melatonin during human pregnancy. Acta Endocrinol 1991; 124: 233-7.

8. Schlabritz-Loutsevitch N, Hellner N, Middendorf R, Müller D, Olcese J. The human myometrium as a target for melatonin. J Clin Endocrinol Metab 2003; 88: 908-13. [CrossRef]

9. Steffens F, Zhou XB, Sausbier U, Sailer C, Motejlek K, Ruth P, et al. Melatonin receptor signaling in pregnant and nonpregnant rat uterine myocytes as probed by large conductance $\mathrm{Ca} 2+$-activated $\mathrm{K}+$ channel activity. Mol Endocrinol 2003; 17: 2103-15. [CrossRef]

10. Olcese J. Circadian aspects of mammalian parturition: a review. Mol Cell Endocrinol 2012; 349: 62-7. [CrossRef]

11. Sharkey JT, Puttaramu R, Word RA, Olcese J. Melatonin synergizes with oxytocin to enhance contractility of human myometrial smooth muscle cells. J Clin Endocrinol Metab 2009; 94: 421-7. [CrossRef]

12. Parlakpinar H, Sahna E, Ozer M.K, Ozugurlu F, Vardi N, Acet A. Physiological and pharmacological concentrations of melatonin protect against cisplatin-induced acute renal injury. J Pineal Res 2002; 33: 161-6. [CrossRef]

13. Mukherjee D, Roy SG, Bandyopadhyay A, Chattopadhyay A, Basu A, Mitra E, et al. Melatonin protects against isoproterenol-induced myocardial injury in the rat: Antioxidative mechanisms. J Pineal Res 2010; 48: 251-62. [CrossRef]

14. Tas U, Ogeturk M, Meydan S, Kus I, Kuloglu T, Ilhan N, et al. Hepatotoxic activity of toluene inhalation and protective role of melatonin. Toxicol Ind Health 2011; 27: 465-73. [CrossRef]

15. Reiter RJ, Manchester LC, Tan DX. Neurotoxins: free radical mechanisms and melatonin protection. Curr Neuropharmacol 2010; 8: 194-210. [CrossRef]

16. Gross GH. A technique for sustained synchronization of hamster estrous cycles by hormonal means. Horm Behav 1977; 9: 23-31. [CrossRef]

17. Khvedelidze BV. Hilbert transform. In Hazewinkel M. Encyclopedia of Mathematics. New York: Springer; 2001.

18. Ayar A, Kutlu S, Yilmaz B, Kelestimur H. Melatonin inhibits spontaneous and oxytocin-induced contractions of rat myometrium in vitro. Neuroendocrinol Lett 2001; 22: 199-207.

19. Ma"rtensson LG, Andersson ERGG, Berg G. Melatonin together with noradrenalin augments contractions of human myometrium. Eur J Pharmacol 1996; 316: 273-5. [CrossRef]
20. Sharkey JT, Puttaramu R, Word RA, Olcese J. Melatonin synergizes with oxytocin to enhance contractility of human myometrial smooth muscle cells. J Clin Endocrinol Metab 2009; 94: 421-7. [CrossRef]

21. Taketani T, Tamura H, Takasaki A, Lee L, Kizuka F, Tamura I, et al. Protective role of melatonin in progesterone production by human luteal cells. J Pineal Res 2011; 51: 207-13. [CrossRef]

22. Schlabritz-Loutsevitch N, Hellner N, Middendorf R, Müller D, Olcese J. The human myometrium as a target for melatonin. J Clin Endocrinol Metab 2003; 88: 908-13. [CrossRef]

23. Gimeno MF, Landa A, Sterin-Speziale N, Cardinali DP, Gemeno AL. Melatonin blocks in vitro generation of prostaglandin by the uterus and hypothalamus. Eur J Pharmacol 1980; 62: 309-17. [CrossRef]

24. Abd-Allah AR, El-Sayed el SM, Abdel-Wahab MH, Hamada FM. Effect of melatonin on estrogen and progesterone receptors in relation to uterine contraction in rats. Pharmacol Res 2003; 47: 349-54. [CrossRef]

25. Celik O, Tagluk ME, Hascalik S, Elter K, Celik N, Aydin NE. Spectrotemporal changes in electrical activity of myometrium due to recombinant follicle-stimulating hormone preparations follitropin alfa and beta. Fertil Steril 2008; 90: 1348-56. [CrossRef]

26. Reiter RJ, Coto-Montes A, Boga JA, Fuentes-Broto L, Rosales-Corral S, Tan DX. Melatonin: New applications in clinical and veterinary medicine, plant physiology and industry. Neuro Endocrinol Lett 2011; 32: 575-87.

27. Ananth CV, Vintzileos AM. Epidemiology of preterm birth and its clinical subtypes. J Matern Fetal Neonatal Med 2006; 19: 773-82. [CrossRef]

28. McCormick MC, Litt JS, Smith VC, Zupancic JA. Prematurity: An overview and public health implications. Annu Rev Public Health 2011; 32: 367-79. [CrossRef]

29. Kenyon AP, Peebles D. Myth: Tocolysis for prevention of preterm birth has a major role in modern obstetrics. Semin Fetal Neonatal Med 2011; 16: 242-6. [CrossRef]

30. Parlakpinar H, Acet A, Gul M, Altinoz E, Esrefoglu M, Colak C. Protective effects of melatonin on renal failure in pinealectomized rats. Int J Urol 2007; 14: 743-8. [CrossRef] 